\title{
Determination of the Rate of Need for Relining Complete Dentures in Patients Referring to a Department of Prosthodontics
}

Ramin Negahdari ${ }^{1}$, Seyyed Mahdi Vahid Pakdel ${ }^{2}$, Sepideh Bohluli ${ }^{3}$, Vahid Fakhrzadeh ${ }^{1}$, Alireza Pournasrollah ${ }^{1 *}$

1. Assistant Professor, Department of Prosthodontics, Faculty of Dentistry, Tabriz University of Medical Science, Tabriz, Iran

2. Post-graduate student, Department of Prosthodontics, Faculty of Dentistry, Tabriz University of Medical Science, Tabriz, Iran

3. Assistant Professor, Department of Oral Medicine, Faculty of Dentistry, Tabriz University of Medical Science, Tabriz, Iran

\begin{abstract}
Introduction: Complete edentulous patients are an important part of prosthodontics department referrals. After a while of prosthetic use, complications such as loosening, tissue irritation, and inefficiency in chewing or change the appearance, cause the need of reline. The purpose of present study is evaluation of complete prosthesis relining needs in patients referring to removable prosthodontics department of Tabriz dentistry faculty in 2014. Materials \& Methods: This retrospective study was conducted on 96 patients that referred to removable prosthetic department in dental faculty of Tabriz by questionnaire and clinical examination. Data were analyzed in SPSS21 software. In this study, $P$ value less than 0.05 was considered statistically significant.

Results: $61.5 \%$ of patients were men and mostly were in 51-60 years old group. $83.3 \%$ had U-shaped ridge and $16.7 \%$ had $V$-shaped ridge. $5.2 \%$ of patients only in upper denture and $11.5 \%$ of them only in lower denture were required to reline. Also $8.3 \%$ of patients in both upper and lower denture were needed reline.75\% didn't need to denture reline. Needs to reline were more in U-shaped ridge. Conclusions: Finally, the results of statistical analysis show that there was a significant relationship between need of reline and the residual ridge but there was not a significant relationship between need of reline and gender and also the time of the prosthesis is going to delivery.
\end{abstract}

Keywords: Complete edentulous; Relining; Prosthesis;

\section{Introduction}

Treatment of edentulous patients other hand, the maximum efficacy of these constitutes an important proportion of prostheses depends on their successful prosthetic treatments. The routine treatment is harmony with the patient's oral functions (2). the use of complete dentures which are In patients with complete edentulism of the inexpensive and easy to fabricate (1). On the mandible, the stability and retention of

\section{Corresponding author:}

Alireza Pournasrollah

Assistant Professor, Department of Prosthodontics, Faculty of Dentistry, Tabriz University of Medical Science, Tabriz, Iran

Email: pournasrollah@razi.tums.ac.ir

Receive date: 2016-02-01| Accept date: 2016-03-26| Publish date: 2016-04-19

DOI: 10.7575/aiac.abcmed.16.04.02.03 
complete denture is a serious problem. It has been shown that there is a direct relationship between the retention of prosthesis and patient satisfaction (1). Bone resorption over time in the edentulous ridge is an important issue that results in a significant decrease in the retention and stability of prosthesis. Such a problem is more severe in the mandible compared to the maxilla due to a smaller prosthetic bed in the mandible (1-4).

After wearing the dentures for some time, some problems arise, including denture mobility, tissue injuries, masticatory inefficacy and changes in appearance. These problems are attributed to two main reasons: 1) an incorrect and unbalanced occlusal relationship; 2) changes in the supporting structures (5). If the problems are due to an incorrect occlusal relationship, it can be solved by correcting such relationship; however, if the problem is due to changes in the denture-supporting tissues, the only solution is to carry out relining or rebasing procedures. Therefore, the main reasons for relining complete dentures are: loss of retention and stability, a decrease in the vertical dimension of the face, a decrease in tissue support, transverse changes in dentures and correction of the occlusal plane $(3,5)$.

Relining is a procedure carried out for readaptation of dentures with the oral cavity tissues. It is carried out by placing acrylic resin on the denture tissue surface. This restores comfort and stability of the denture and prevents accumulation of food debris under the denture (2).

As mentioned above, several studies have shown that complete dentures might become loose over time, which might result in ulceration, occlusal disturbances and poor function of the dentures (1-5). Therefore, complete dentures might require relining to improve retention, stability, oral hygiene and esthetic. Different relining techniques have been used in dentistry with different success rates (1).

In a study by Knechtel et al, denture loosening, a decrease in ability to chew hard foods, a decrease in ability to pronounce words correctly and denture esthetic-related reasons were reported as the most important reasons for relining complete dentures (5).

In a search carried out in scientific databases almost no studies were found that have evaluated the need for relining and related factors in the north-west of the country. Therefore, considering the large number of individuals wearing complete dentures and the need for attention to dentures as efficient prostheses, the present study was undertaken to determine the rate of need for relining of complete dentures in patients referring to the Removable Prosthesis Division, Department of Prosthodontics, Tabriz Faculty of Dentistry, and the relevant factors in 2013 so that the results of the study would help prepare proper guidelines for educational programs. It is also expected that the results of this study would prove useful for scheduling periodic recall visits for patients wearing complete dentures for carrying out relining procedures.

\section{Materials and Methods}

In the present retrospective study, 96 patients whose complete dentures had been fabricated in the Removable Prosthesis Division, Department of Prosthodontics, Faculty of Dentistry, Tabriz University of Medical Sciences, were selected randomly. The patients were recalled sequentially and examined by the professors in the Department, and the following variables were recorded: the need or lack of need for relining of dentures in each jaw, demographic data of the subjects, the date of denture delivery, the clinician responsible for the fabrication of dentures, the duration of tooth extraction, the ridge form, the type of occlusion, the number of times of denture use, 
the number of previous relining procedures, and the time interval between the delivery of the dentures and the need for relining. To evaluate the need for relining, each subject was examined by the professors and the reasons for relining, including pain, denture loosening and functional problems, were recorded. Finally, Bayer alginate impression material, with soft consistency, was used to confirm the need for relining.

\section{Results}

Of 96 subjects included in this study, $38.5 \%$ and $61.5 \%$ were female and male, respectively (Table 1). Of 96 subjects, $7.3 \%$ were in the $30-$

40 age group, $31.2 \%$ were in the $41-50$ age group, $40.7 \%$ were in the 51-60 age group and $20.8 \%$ were over 61 years of age (Table 2). Of all the patients, $83.3 \%$ had $\mathrm{V}$-shaped ridge and $16.71 \%$ and $16.71 \%$ had $V$-shaped ridge (Table $3)$.

The results of the evaluation of the need for relining of complete dentures in patients referring to the Department of Prosthodontics, Tabriz Faculty of Dentistry, in 2013 showed that $75 \%$ of patients did not need relining of their dentures; $5.2 \%$ and $11.5 \%$ of the subject needed relining of the upper and lower dentures only, respectively, and $8.3 \%$ of the subjects needed relining of both upper and lower dentures (Table 4).

\begin{tabular}{ccccc}
\hline Sex & N & $\begin{array}{c}\text { Percen } \\
\text { tage }\end{array}$ & $\begin{array}{r}\text { Reliable } \\
\text { percentage }\end{array}$ & $\begin{array}{c}\text { Total } \\
\text { percentage }\end{array}$ \\
\hline Male & 59 & 61.5 & 61.5 & 61.5 \\
Female & 37 & 38.5 & 38.5 & 100.0 \\
Total & 96 & 100.0 & 100.0 & \\
\hline
\end{tabular}

Table 1: Frequency distribution of the subjects in terms of gender

\begin{tabular}{ccccc}
\hline Age & $\mathbf{N}$ & $\begin{array}{c}\text { Percen } \\
\text { tage }\end{array}$ & $\begin{array}{r}\text { Reliable } \\
\text { percentage }\end{array}$ & $\begin{array}{c}\text { Total } \\
\text { percentage }\end{array}$ \\
\hline $\mathbf{3 0 - 4 0}$ & 7 & 7.3 & 7.3 & 7.3 \\
$\mathbf{4 1 - 5 0}$ & 30 & 31.2 & 31.2 & 38.5 \\
$\mathbf{5 1 - 6 0}$ & 39 & 40.7 & 40.7 & 79.2 \\
$\mathbf{> 6 1}$ & 20 & 20.8 & 20.8 & 100.0 \\
Total & 96 & 100.0 & 100.0 & \\
\hline
\end{tabular}

Table 2: Frequency distribution of the subjects in terms of age 


\begin{tabular}{lcccc}
\hline $\begin{array}{l}\text { Residual } \\
\text { ridge shape }\end{array}$ & $\mathbf{N}$ & Percentage & $\begin{array}{c}\text { Reliable } \\
\text { percentage }\end{array}$ & $\begin{array}{c}\text { Total } \\
\text { percentage }\end{array}$ \\
\hline $\begin{array}{l}\text { U-shaped } \\
\text { ridge }\end{array}$ & 80 & 83.3 & 83.3 & 83.3 \\
$\begin{array}{l}\text { V-shaped } \\
\text { ridge }\end{array}$ & 16 & 16.7 & 16.7 & 100.0 \\
$\begin{array}{l}\text { Total } \\
\text { prdal }\end{array}$ & 96 & 100.0 & 100.0 & \\
\hline
\end{tabular}

Table 3: Frequency distribution of the subjects in terms of the shape of the ridge

\begin{tabular}{ccccc}
\hline Need for relining & N & $\begin{array}{c}\text { Perce } \\
\text { ntage }\end{array}$ & $\begin{array}{r}\text { Reliable } \\
\text { percentage }\end{array}$ & $\begin{array}{c}\text { Total } \\
\text { percentage }\end{array}$ \\
\hline $\begin{array}{c}\text { Need for relining } \\
\text { in the maxilla }\end{array}$ & 5 & 5.2 & 5.2 & 5.2 \\
$\begin{array}{c}\text { Need for relining } \\
\text { in the mandible } \\
\text { Need for relining } \\
\text { in both arches } \\
\quad \text { No need for } \\
\text { relining }\end{array}$ & 11 & 11.5 & 11.5 & 16.7 \\
$\quad$ Total & 72 & 75.0 & 75.0 & 100.0 \\
\hline
\end{tabular}

Table 4: Frequency distribution of the subjects in terms of the need for relining of complete dentures

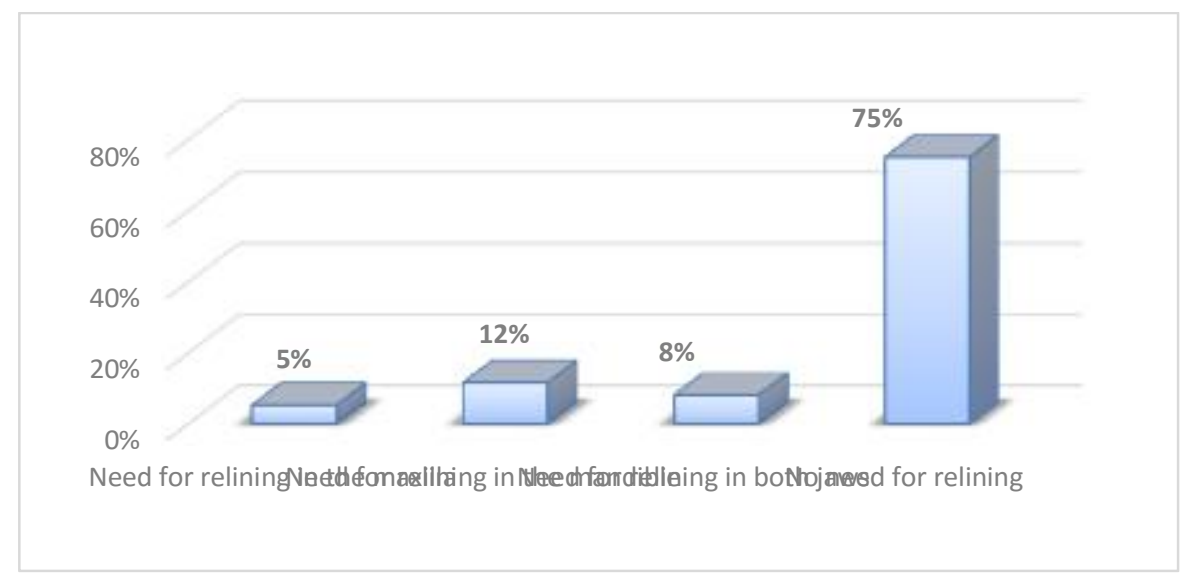

Figure 1: Frequency distribution of the subjects in terms of the need for relining of complete dentures 


\section{Discussion}

One of the methods to replace lost teeth is the use of removable dentures. Prosthodontics is a branch of dentistry that deals with the reconstruction of the lost structures of the oral cavity and also lost teeth to restore oral function, comfort, appearance and health of the patients (3). On the other hand, the maximum efficacy of prostheses depends on their proper harmony with the patients' oral cavity functions (2). Only prostheses have proper function that exhibit proper retention and stability (2). Sometime after beginning of denture wearing, some problems emerge, including denture loosening, tissue injuries, masticatory inefficacy and changes in patient appearance. Relining is carried out to re-adapt the denture base with the oral tissues by placing some acrylic resin on the dentures. Such tissue adaptation procedures can restore comfort and stability of the denture, preventing accumulation of food remnants under dentures (2). Given the large number of individuals who wear complete dentures and the need for attention to dentures as efficacious prostheses, the present study was carried out to determine the need for relining of complete dentures in patients referring to the Removable Prosthesis Division, Department of Prosthodontics, Tabriz Faculty of Dentistry, and the relevant factors in 2013.

Of 96 subjects in the present study, who referred to the Department of Prosthodontics, Tabriz Faculty of Dentistry, 38.5\% and $61.5 \%$ were female and male, respectively; $7.3 \%$, $31.2 \%$ and $40.7 \%$ were in the $30-40,41-50$ and 51-60 age groups, respectively, and $20.8 \%$ were over 61 years of age. In relation to the ridge form, $83.3 \%$ had U-shaped and $16.71 \%$ had V-shaped residual ridges. The results showed that $5.2 \%$ and $11.5 \%$ of the subjects needed relining only in the maxillary or mandibular arches, respectively, and $8.3 \%$ required relining of dentures in both arches. In addition, $75 \%$ of the patients did not require any relining for their dentures.

Furthermore, of patients with U-shaped ridges, $5.2 \%$ required relining of their upper dentures, $11.5 \%$ required relining of their lower dentures and $5.2 \%$ required relining of both upper and lower dentures. However, only 3.1\% of patients with $\mathrm{V}$-shaped ridges required relining of both upper and lower dentures. Chisquared tests showed that the difference between these two ridge forms was significant, with more patients with U-shaped ridges requiring relining of their dentures.

On the other hand, although the need for relining of dentures in males, which had been delivered 6-12 months previously, was higher than that of dentures in women, delivered 3-6 months previously, chi-squared test showed that the difference was not significant.

A search in databases did not bring up a study that has evaluated the need for relining. However, there are several studies available that have shown the effect of ridge morphology on retention and stability of complete dentures and finally the patients' satisfaction and an increase in masticatory efficacy (6-11).

In a study by Ribeiro et al, the anatomy of the residual ridge had a significant role in the stability and retention of dentures; in this context, $82 \%$ of patients who complained of loose dentures after treatment had flat ridges (9).

It was concluded in a study by Takayama et al that the height and form of the residual ridge had a significant role in preventing denture dislodgment under unilateral or bilateral forces (10). Batt et al concluded that both the patient's oral cavity conditions and the quality of the dentures fabricated affect the success of dentures (11). However, Celebi et al showed no relationship between the form and quality of the residual ridge and the patients' complaint about denture loosening and satisfaction with 
complete dentures; in this context, patients with high ridges, too, exhibited low satisfaction with their dentures (12).

Finally, considering the limited number of studies and their contradictory results in this field and the ever-increasing use of dental prostheses, further studies are necessary so that better dentures can be fabricated and more favorable services can be rendered to patients.

The reason for the relationship between relining rate and $U$-shaped ridges might be the extent of ridge resorption. In this context, there is a short interval since tooth extraction in $\mathrm{U}$ shaped ridges; therefore, more resorption will take place during the first year, leading to greater need for relining. However, in more smooth ridges, the bulk of resorption has already taken place and the resorption occurring during this interval is not great enough to necessitate relining.

Considering the results of this study, the high rate of need for relining removable dentures and the problems associated with not relining dentures, it is necessary to revise the educational and continuous education programs so that the importance and the mechanism of this procedure can be further explained to dentists.

It is hoped that the results of this study would result in taking it more serious to recall patients wearing complete dentures.

\section{Conclusion}

It was concluded from the results of the present study that:

1. $25 \%$ of the dentures fabricated in the Department of Prosthodontics required a relining procedure.

2. There was a significant relationship between the shape of the residual ridge and the need for relining, with greater need for relining in $\mathrm{U}$-shaped ridges.

3. No significant relationship was detected between the need for relining and patient gender and the time internal since the delivery of the dentures.

\section{References}

1. Mahshid M, Hadi A, Sabori A, Sadr J. Effect of implant position on retention and stability of the implant supported overdentures. Journal of Dental School Shahid Beheshti University of Medical Sciences. 2013;30(1):40.

2. Asadzadeh N, Gorbanfard F, Garachahi M, Ezaz A. Effect of relining methods on the posterior palatal seal. Journal of Mashhad Dental School. 2014;37(1):12.

3. Hicky J, Zarb G, Bolender C. Boucher's prosthodontic: treatment for edentulous patient. 13 ed. The C.V.Mosby Co: St.Louis; 2013. p. 3.

4. Misch C. Contemporary implant dentistry. 3 ed. The C.V. Mosby Co: St.Louis:; 2008.

5. Knechtel M, Loney R. Improving the Outcome of Denture Relining. JCDA. 2007;73(7):587.

6. Borie E, Orsi IA, Fuentes R, Beltran V, Navarro P, Pareja F, et al. Maximum bite force in elderly indigenous and nonindigenous denture wearers. Acta odontologica latinoamericana : AOL. 2014;27(3):115-9.

7. Dendukuri G, Bindra S, Mohan AP, Sumanth Krishna T. Functional and esthetic rehabilitation in a partially edentulous patient: a case report. Journal of maxillofacial and oral surgery. 2012;11(4):473-6.

8. Atwood D. Essentials of complete denture prosthodontics. In: Winkler S, editor. The problem of reduction of residual ridges. Philadelphia: Saunders;. 1979:74.

9. Ribeiro JA, de Resende CM, Lopes AL, Farias-Neto A, Carreiro Ada F. The influence of mandibular ridge anatomy on treatment outcome with conventional complete dentures. Acta odontologica latinoamericana : AOL. 2014;27(2):53-7. 10. Takayama Y, Sasaki H, Goto M, Mizuno K, Saito M, Yokoyama A. Morphological factors of mandibular edentulous alveolar ridges influencing the movement of dentures calculated using finite element analysis. Journal of prosthodontic research. 2011;55(2):98-103. 
11. de Baat C, van Aken AA, Mulder J, Kalk W. "Prosthetic condition" and patients' judgment of complete dentures. The Journal of prosthetic dentistry. 1997;78(5):472-8.

12. Celebic A, Knezovic-Zlataric D, Papic M, Carek V, Baucic I, Stipetic J. Factors related to patient satisfaction with complete denture therapy. The journals of gerontology Series A, Biological sciences and medical sciences.

2003;58(10):M948-53. 